\title{
Polímeros Eletrônicos: Novos Materiais para o Século 21 e suas Potenciais Aplicações no Agronegócio
}

Quando na década de 70, mais especificamente no ano de 1977, ocorreu a inicial e histórica descoberta de que o polyacetileno $(\mathrm{CH})_{\mathrm{x}}$ (conhecido como o protótipo do polímero condutor), poderia ser dopado em ambas as formas, p- ou n-, tanto química ou eletroquimicamente, sendo levado até o seu estado metálico, constatou-se que uma nova e importante página, de um novo capitulo na história da ciência de materiais poliméricos, estava sendo escrita. A descoberta dos polímeros orgânicos que possuem propriedades óticas, magnéticas, elétricas e eletrônicas de um metal, mantendo as propriedades mecânicas, de processabilidade, entre outras, comumente associada com polímeros convencionais, realizada nos laboratórios da Universidade da Pensilvania (UPENN), pelos Professores Dr. Alan G. MacDiarmid (Departamento de Química da UPENN, EUA), Dr. Hideki Shirakawa (Instituto de Ciência de Materiais da Universidade de Tsukuba, Japão) e Dr. Alan J. Heeger (Departamento de Física da Universidade da California em Santa Barbara, EUA), levou à investigação de outros polímeros condutores e em 1990 tornou-se de especial importância tecnológica com o seu uso em diodos emissores de luz. Vários prêmios e láureas da área cientifica e tecnológica foram concedidos aos pesquisadores, mas um dos grandes reconhecimentos da comunidade veio com a premiação outorgada pela Academia Real de Ciência da Suécia, com o prêmio Nobel de Química de 2000 aos três pesquisadores.

Atualmente os plásticos condutores e semicondutores estão sendo utilizados na pesquisa e desenvolvimento de dispositivos eletrônicos com características de baixo custo e descartável, utilizando impressoras jato de tinta e técnica de "Line Patterning", desenvolvida pelo grupo de pesquisa do Prof. MacDiarmid para o desenvolvimento de sensores a base de plástico e papel, polímeros emissores de luz (onde de acordo com a revista "The Economist" deverá se tornar uma industria de bilhões de dólares), transistor de efeito de campo totalmente plástico, com aplicações em identificadores por radio-freqüência e memórias plásticas que possam armazenar dados mesmo quando a energia do dispositivo está desligada, são alguns dos exemplos.

Um dos trabalhos que vem sendo realizado em colaboração com o grupo do Prof. MacDiarmid, na UPENN, por pesquisadores da Embrapa Instrumentação Agropecuária, é a pesquisa utilizando a técnica de "Line Patterning" para desenvolvimento de sensores a base de plástico, papel e polímeros condutores com características de baixo custo e descartável para aplicações no agronegócio e agricultura familiar. A união de técnicas da fronteira do conhecimento como polímeros condutores e nanotecnologia estão sendo aplicadas no desenvolvimento de instrumentação agropecuária.

Matéria elaborada por: Paulo Sérgio de Paula Herrmann Jr., Pesquisador da Embrapa Instrumentação Agropecuária - São Carlos e Pesquisador Associado da Universidade Texas em Dallas junto a Universidade da Pensilvania

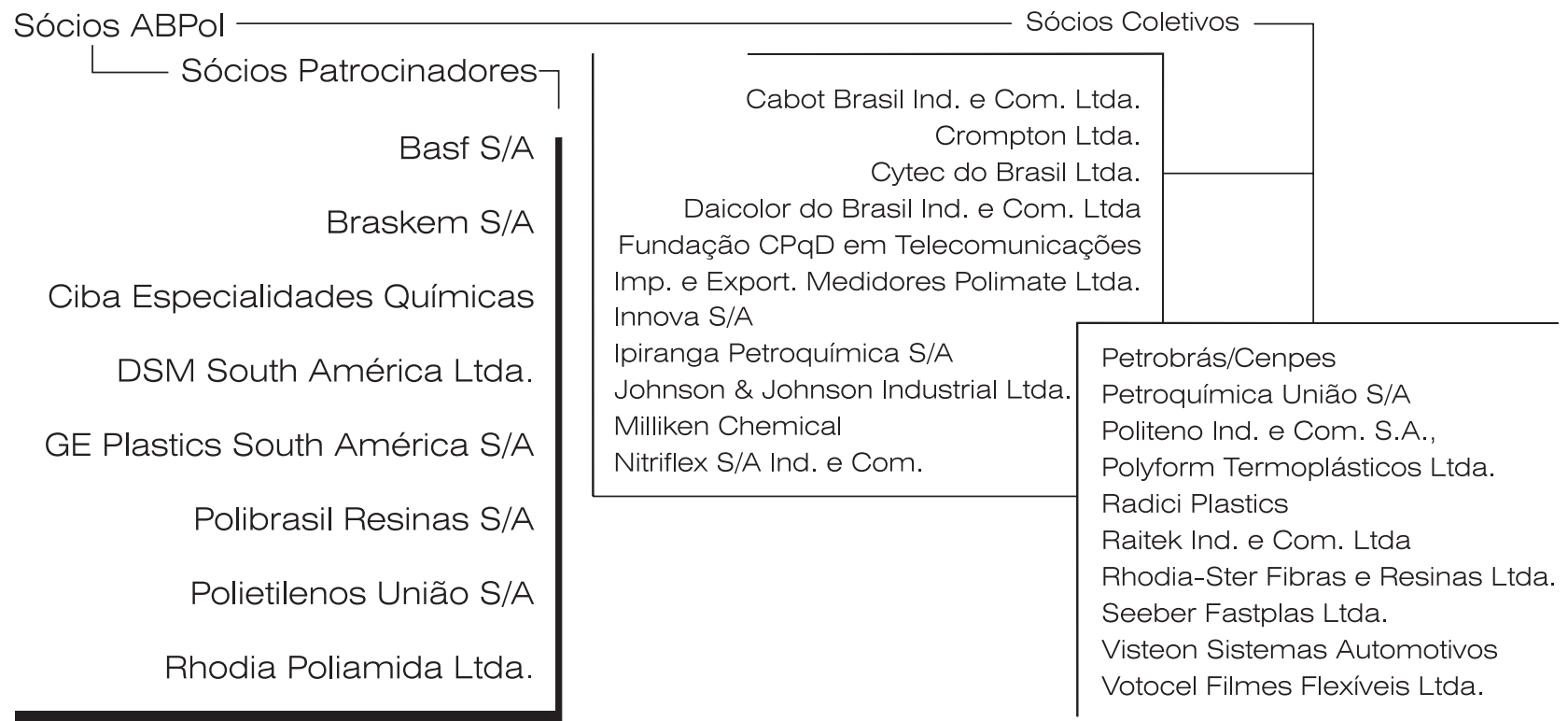

